\title{
Based on the Theory of Grey System to Forecast China's Business Volume of Express Services
}

\author{
Shiyin Tang, Guangming Deng* \\ College of Science, Guilin University of Technology, Guilin, China \\ Email: $\underline{\text { dgm@@glut.edu.cn }}$
}

Received 23 January 2015; accepted 10 February 2010; published 12 February 2015

Copyright (C) 2015 by authors and Scientific Research Publishing Inc.

This work is licensed under the Creative Commons Attribution International License (CC BY). http://creativecommons.org/licenses/by/4.0/

\section{(c) (i) Open Access}

\begin{abstract}
With the rapid growth of economy, the popularization of the Internet, the rise of online shopping, China's express delivery industry showed rapid growth trend, and the competition of the express industry market is becoming increasingly fierce. According to the data of business volume of express services from 2001 to 2013 , this paper analyzes the factors affecting China's business volume of express services through the grey correlation degree analysis, and forecasts express business volume in 2014 and 2015 by using the grey forecasting method to establish GM (1,1) model.
\end{abstract}

\section{Keywords}

Business Volume of Express Services, Grey Correlation Degree, Grey Forecasting Method

\section{Introduction}

Express industry development in our country has experienced three stages, rose in 1980s and developed in 1990s and transformed in 21st century. It has become an indispensable part of the national economy. Express, also called Courier, means that express company fast delivers the goods for the customer with efficient, safe and door to door logistics activities by road, rail and air transport. Recently, China's express industry development is more and more rapid and has become an integral part of the national economy of our country. The common express are Zhaijisong, Tiantian, EMS, Yuantong, Shentong, Shunfeng, Zhongtong, Yunda, etc. As of the end of 2011, express delivery companies that hold business licenses of China have more than 7500 . According to statistics, business volume of express services is growing at 38.29\% a year on average in 2007 to 2013, and in 2013 the business volume of express services is 9.19 billion, year-on-year growth is $61.65 \%$. Now express industry "Corresponding author. 
presents a diversified pattern, also forms a state-owned, private and foreign company pattern in the competing markets [1]. With the rapid development of express delivery, express delivery of related research has also drawn the attention of many scholars, but the current academic circles in express business factors and statistical research of prediction are relatively rare.

In order to analyze and research business volume of express services in our country intuitively, this paper tries to explore the influencing factors of business volume of express services and get the influential factors through the grey correlation analysis, and puts forward corresponding suggestions on the development of express delivery industry in the future. The advantage of the development in China's express industry is that development is rapid, market space is large and the development of electronic commerce brings huge demand [2]. At the same time, we choose the grey prediction GM $(1,1)$ model [3] to predict the business volume of express services in the future two years and to provide the reference for its developing tendency.

\section{Grey Correlation Analysis}

The grey system theory is a new theory put forward by Professor Deng Julong in 1982, the theory of incomplete information system is using specific method described, forecasting, decision-making and control system theory [4]. Grey system's internal part of the information is known, the other part of the information is unknown, the relationship between various factors is uncertain, it is between white and black system, and white system refers to the internal characteristics of fully known, and black system refers to the outside world knew nothing about the system of internal information, only through their contact with the outside world to observational studies. Grey system theory is the extension of cybernetics theory and method, in which any random process as grey process, is in a certain time zone and amplitude and changes the amount of grey from the system research of the relationship between information, namely the use of known information to reveal the unknown information. So, we use grey correlational analysis method to analyze the correlation degree among various factors of the system.

To explore the relationship between business volume of express services and the influencing factors, initially determined factors are GDP, number of Internet users, freight ton-kilometers, light industry value, total value of imports and exports of goods, total retail sales of consumer goods, consumer spending [5], we use grey correlation analysis method to calculate the grey correlation degree, and get the strength of the associated degree.

Grey correlation calculation steps are as follows [6]:

1) Initialize data;

$$
X_{i}=\left\{\frac{Y_{i}(1)}{Y_{i}(1)}, \frac{Y_{i}(2)}{Y_{i}(1)}, \frac{Y_{i}(3)}{Y_{i}(1)}, \cdots, \frac{Y_{i}(n)}{Y_{i}(1)}\right\} \quad i=0,1,2, \cdots, m
$$

2) Compute absolute difference sequence $\Delta$;

$$
\Delta_{i}=\left|X_{0}(k)-X_{i}(k)\right| \quad i=1,2, \cdots, m, k=1,2, \cdots, n
$$

3) Compute correlation coefficient $\eta$;

$$
\eta(k)=\frac{\min \min \left|\hat{X}^{(0)}(k)-X^{(0)}(k)\right|+\rho \max \max \left|\hat{X}^{(0)}(k)-X^{(0)}(k)\right|}{\left|\hat{X}^{(0)}(k)-X^{(0)}(k)\right|+\rho \max \max \left|\hat{X}^{(0)}(k)-X^{(0)}(k)\right|} \quad k=1,2, \cdots, n
$$

4) Compute correlation $r$.

$$
r=\frac{1}{n} \sum_{k=1}^{n} \eta(k)
$$

According to data of business volume of express services, GDP (F1), number of Internet users (F2), freight ton-kilometers (F3), light industry value (F4), total value of imports and exports of goods (F5), total retail sales of consumer goods (F6), consumer spending (F7) in 2001 to 2013 from China Statistical Yearbook [7], computing results of grey correlation degree is shown in Table 1. The data is shown in the Appendix.

Table 1 shows that the order of correlation degree is number of Internet users, light industry value, GDP, total value of imports and exports of goods, total retail sales of consumer goods, freight ton-kilometers, consumer spending. 
Table 1. The variable correlation calculation results and order.

\begin{tabular}{ccccccccc}
\hline & F1 & F2 & F3 & F4 & F5 & F6 & F7 \\
\hline Correlation Degree & 0.7859 & 0.8449 & 0.7957 & 0.7831 & 0.7801 & 0.7858 & 0.7776 \\
Order & 3 & 1 & 2 & 5 & 6 & 4 & 7 \\
\hline
\end{tabular}

\section{Grey Forecasting Model}

\subsection{Grey Forecasting Method Principle and Steps}

Grey forecasting method contains uncertainty system prediction method through generating the original data, the correlation analysis is carried out on the system factors to determine the development trend of system factors in different degree, find the rule of system changes and generate strong regularity of the data sequence, then build the corresponding differential equation model to predict the future trend of the development. The calculation steps of setting GM $(1,1)$ model are as follows:

1) Construct the accumulation generation;

$$
X^{(1)}(k)=\sum_{i=1}^{n} X^{(0)}(i)=X^{(1)}(k-1)+X^{(0)}(k)
$$

2) Construct matrix $B$ and vector data $Y_{n}$;

$$
B=\left[\begin{array}{lr}
-\frac{1}{2}\left[X^{(1)}(1)+X^{(1)}(2)\right] & 1 \\
-\frac{1}{2}\left[X^{(1)}(2)+X^{(1)}(3)\right] & 1 \\
-\frac{1}{2}\left[X^{(1)}(3)+X^{(1)}(4)\right] & 1 \\
-\frac{1}{2}\left[X^{(1)}(4)+X^{(1)}(5)\right] & 1
\end{array}\right] \quad Y_{n}=\left[\begin{array}{l}
X^{(0)}(2) \\
X^{(0)}(3) \\
X^{(0)}(4) \\
X^{(0)}(5)
\end{array}\right]
$$

3) Compute $B^{\mathrm{T}} B,\left(B^{\mathrm{T}} B\right)^{-1}$ and $B^{\mathrm{T}} Y_{n}$, though $\hat{\alpha}$ to get $\alpha$ and $\mu$;

$$
\hat{a}=\left(B^{\mathrm{T}} B\right)^{-1} B^{\mathrm{T}} Y_{n}
$$

4) Get prediction model;

Corresponding differential equations of GM $(1,1)$ model is:

$$
\frac{\mathrm{d} X^{(1)}}{\mathrm{d} t}+a X^{(1)}=\mu
$$

The prediction model is:

$$
\hat{X}^{(1)}(k+1)=\left[X^{(0)}(1)-\frac{\mu}{a}\right] \mathrm{e}^{-a k}+\frac{\mu}{a} \quad k=1,2, \cdots, n
$$

After get GM $(1,1)$ model, it needs to determine whether the model is suitable for predicting and inspecting model, including residual test, correlation test and posterior difference test, their steps are as follows:

1) Residual test.

According to the prediction model calculation $\hat{X}^{(1)}(i)$ cumulative minus to generate $\hat{X}^{(0)}(i)$, then compute absolute error sequence $\Delta^{(0)}(i)$ and relative error sequence $\Phi(i)$ of the original sequence $X^{(0)}(i)$ and $\hat{X}^{(0)}(i)$.

$$
\begin{gathered}
\Delta^{(0)}(i)=\left|X^{(0)}(i)-\hat{X}^{(0)}(i)\right| \quad i=1,2, \cdots, n \\
\Phi(i)=\frac{\Delta^{(0)}(i)}{X^{(0)}(i)} \times 100 \% \quad i=1,2, \cdots, n
\end{gathered}
$$


2) Correlation test.

Compute correlation coefficient and correlation degree of $\hat{X}^{(0)}(i)$ and the original sequence $X^{(0)}(i)$, when $\rho$ is 0.5 , the correlation degree is more than 0.6 .

3) Posterior difference test.

Compute standard deviation of the original sequence $X^{(0)}(i)$ :

$$
S_{1}=\sqrt{\frac{\sum\left[X^{(0)}(i)-\bar{X}^{(0)}\right]^{2}}{n-1}}
$$

Compute standard deviation of the absolute error sequence $\Delta^{(0)}(i)$ :

$$
S_{2}=\sqrt{\frac{\sum\left[\Delta^{(0)}(i)-\bar{\Delta}^{(0)}\right]^{2}}{n-1}}
$$

Compute variance ratio:

$$
C=\frac{S_{2}}{S_{1}}
$$

Compute small error probability:

$$
P=p\left\{\left|\Delta^{(0)}(i)-\bar{\Delta}^{(0)}\right|<0.6745 S_{1}\right\}
$$

If $e_{i}=\left|\Delta^{(0)}(i)-\bar{\Delta}^{(0)}\right|, \quad S_{0}=0.6745 S_{1}$, then $P=p\left\{e_{i}<S_{0}\right\}$.

The posteriori difference test discriminant rules:

$$
\begin{array}{|c|c|c}
P & C & \\
>0.95 & <0.35 & \text { Good } \\
>0.80 & <0.50 & \text { Qualified } \\
>0.70 & <0.65 & \text { Barely qualified } \\
\leq 0.70 & \geq 0.65 & \text { Unqualified }
\end{array}
$$

If the residual test, correlation test and posterior inspection pass, then it can use the model to forecast [8].

\subsection{Build Model}

According to the data of business volume of express services in 2009 to 2013 from China Statistical Yearbook, which is shown in the Appendix:

$$
a=-0.4525, \mu=93199.6474, \frac{\mu}{a}=-205977.190, X^{(0)}(1)-\frac{\mu}{a}=391762.990
$$

So GM $(1,1)$ model is:

$$
X^{(1)}(k+1)=391762.990 \mathrm{e}^{0.4525 k}-205977.190
$$

\subsection{Model Test}

1) Residual test for model, to get the average relative error is $3.19 \%$, less than $5 \%$, through the test.

2) Correlation test for model, to get the correlation degree is 0.66 , less than 0.6 , through the test.

3) Posterior difference test for model, to get $P=1$ more than $0.95, C=0.06$ less than 0.35 , through the test.

Thus the model $X^{(1)}(k+1)=391762.990 \mathrm{e}^{0.4525 k}-205977.190$ through residual test, correlation test and posterior difference test, it can use the model to predict business volume of express service.

When $k=5$, the predict value is:

$$
X^{(0)}(6)=X^{(1)}(6)-X^{(1)}(5)=1369624.25
$$


When $k=6$, the predict value is:

$$
X^{(0)}(7)=X^{(1)}(7)-X^{(1)}(6)=2153322.52
$$

The predict value of business volume of express service is 13,696 million in 2014 and 21,533 million in 2015.

\section{Conclusions and Advice}

This paper through the statistical analysis of influencing factors and prediction analysis of business volume of express services can get the following conclusions and advice.

1) Though grey correlation degree, it shows that the influence of number of Internet users for business volume of express services is the most, the correlation degree is 0.8449 . Then light industry value (correlation degree is 0.7957), GDP (correlation degree is 0.7859), total value of imports and exports of goods (correlation degree is 0.7858), total retail sales of consumer goods (correlation degree is 0.7831 ), freight ton-kilometers (correlation degree is 0.7801 ), consumer spending (correlation degree is 0.7776 ). That is to say, the correlation degree is more than 0.77 , the influence of influencing factors for business volume of express services is strong. Number of Internet users in influencing factors is the strongest, the reason may be that in recent years the rise of online shopping, to a certain extent, promotes the growth of business volume of express services [9]. The second is light industry value, due to the transportation of light industrial products mostly depends on the express. Correlation effect of consumer spending is relatively small, because consumer spending includes not only food, clothing, stationery, based partly on express transportation expenses, also the bank intermediary services, health care, insurance services, transportation and communications, house that needn't express transportation cost, thus leads to the smaller of correlation between consumer spending and business volume of express services.

2) Though grey forecasting model building GM $(1,1)$ model, the predict value of business volume of express service is 13,696 million in 2014 and 21,533 million in 2015. Express delivery business is growing rapidly, which encourages the development of multiple industries and establishes relations of cooperation with express industry; it also makes efforts to develop the express business services in terms of business development in various fields, and strengthen the construction of express delivery business, making the express industry become a diversified and diversified industry [10]. So express delivery enterprises can build their own e-commerce platform and make the express industry into multi-level industries because of the above analysis, and we can see the development of e- commerce industry to a large extent influences the development of the express industry.

\section{Acknowledgements}

This work was jointly supported by the National Social Science Fund (No. 13BTJ009), the National Natural Science Fund (No. 61004101) and Guangxi Key Laboratory of Spatial Information and Geomatics (No. 1207115-27).

\section{References}

[1] Li, J.Y. (2011) Based on the Development of the Industry Association of China’s Express Delivery Industry Research. Shanghai Normal University, Shanghai.

[2] Peng, L.C. (2011) Analysis of the Advantages and Disadvantages of China's Express Industry Development. Market Modernization, 656, 40-41.

[3] Wang, L.H. (2012) Based on GM(1,1) Model to Forecast China’s Revenue from Express Service. Logistics Technology, 31, 84-86.

[4] Cao, M.X. (2007) Research on Grey Incidence Analysis Model and Its Application. Nanjing University of Aeronautics and Astronautics, Nanjing.

[5] Wang, W.T. and Huang, B.Z. (2011) An Empirical Study of Influencing Factors in the Express Industry Development. China Logistics \& Purchasing, 13, 74-75.

[6] Deng, J.L. (1990) The Grey System Theory Tutorial. Huazhong University of Science and Technology Press Co., Ltd., Wuhan.

[7] (2014) China Statistical Yearbook. National Bureau of Statistics of China, Beijing.

[8] Xu, G.X. (2008) Statistical Forecasting and Decision-Making. 3rd Edition, Shanghai University of Finance \& Economics Press Co., Ltd., Shanghai. 
[9] Wu, H.R. (1990) Applied Grey Model to Forecast Business Volume of Postal and Postal and Telecommunication Services. Journal of Nanjing Institute of Posts and Telecommunications, 10, 91-94.

[10] Ji, T. (2012) Analysis of Influencing Factors on Express Industry. Nanjing University of Posts and Telecommunications, Nanjing.

\section{Appendix}

The data of business volume of express services in 2009 to 2013 in China.

\begin{tabular}{|c|c|c|c|c|c|c|c|c|}
\hline Year & $\begin{array}{l}\text { Business } \\
\text { Volume of } \\
\text { Express } \\
\text { Services }\end{array}$ & GDP & $\begin{array}{c}\text { Number of } \\
\text { Internet } \\
\text { Users }\end{array}$ & $\begin{array}{c}\text { Light } \\
\text { Industry } \\
\text { Value }\end{array}$ & $\begin{array}{l}\text { Total Retail } \\
\text { Sales of } \\
\text { Consumer } \\
\text { Goods }\end{array}$ & $\begin{array}{c}\text { Freight } \\
\text { Ton-kilometers }\end{array}$ & $\begin{array}{l}\text { Total Value } \\
\text { of Imports } \\
\text { and Exports } \\
\text { of Goods }\end{array}$ & $\begin{array}{l}\text { Consumer } \\
\text { Spending }\end{array}$ \\
\hline 2001 & 12652.7 & 109655.2 & 3370.0 & 37636.9 & 43055.4 & 47710.0 & 42183.6 & 49435.9 \\
\hline 2002 & 14036.2 & 120332.7 & 5910.0 & 43355.7 & 48135.9 & 50686.0 & 51378.2 & 53056.6 \\
\hline 2003 & 17237.8 & 135822.8 & 7950.0 & 50497.5 & 52516.3 & 53859.0 & 70483.5 & 57649.8 \\
\hline 2004 & 19771.9 & 159878.3 & 9400.0 & 63819.1 & 59501.0 & 69445.0 & 95539.1 & 65218.5 \\
\hline 2005 & 22880.3 & 184937.4 & 11100.0 & 78280.3 & 67176.6 & 80258.0 & 116921.8 & 72958.7 \\
\hline 2006 & 26988.0 & 216314.4 & 13700.0 & 94845.9 & 76410.0 & 88840.0 & 140974.0 & 82575.5 \\
\hline 2007 & 120189.6 & 265810.3 & 21000.0 & 119640.4 & 89210.0 & 101419.0 & 166863.7 & 96332.5 \\
\hline 2008 & 151329.3 & 314045.4 & 29800.0 & 145429.1 & 114830.1 & 110300.0 & 179921.5 & 111670.4 \\
\hline 2009 & 185785.8 & 340902.8 & 38400.0 & 161498.1 & 132678.4 & 122133.0 & 150648.1 & 123584.6 \\
\hline 2010 & 233892.0 & 401512.8 & 45730.0 & 200071.5 & 156998.4 & 141837.0 & 201722.1 & 140758.6 \\
\hline 2011 & 367311.1 & 472881.6 & 51310.0 & 237699.8 & 183918.6 & 159324.0 & 236402.0 & 164945.2 \\
\hline 2012 & 568548.0 & 518942.1 & 56400.0 & 265865.0 & 210307.0 & 173771.0 & 244160.2 & 190423.8 \\
\hline 2013 & 918674.9 & 568845.0 & 61758.0 & 294758.5 & 234380.0 & 182977.9 & 258300.0 & 234299.0 \\
\hline
\end{tabular}

* Data from China statistical yearbook (2014). 
Scientific Research Publishing (SCIRP) is one of the largest Open Access journal publishers. It is currently publishing more than 200 open access, online, peer-reviewed journals covering a wide range of academic disciplines. SCIRP serves the worldwide academic communities and contributes to the progress and application of science with its publication.

Other selected journals from SCIRP are listed as below. Submit your manuscript to us via either submit@scirp.org or Online Submission Portal.
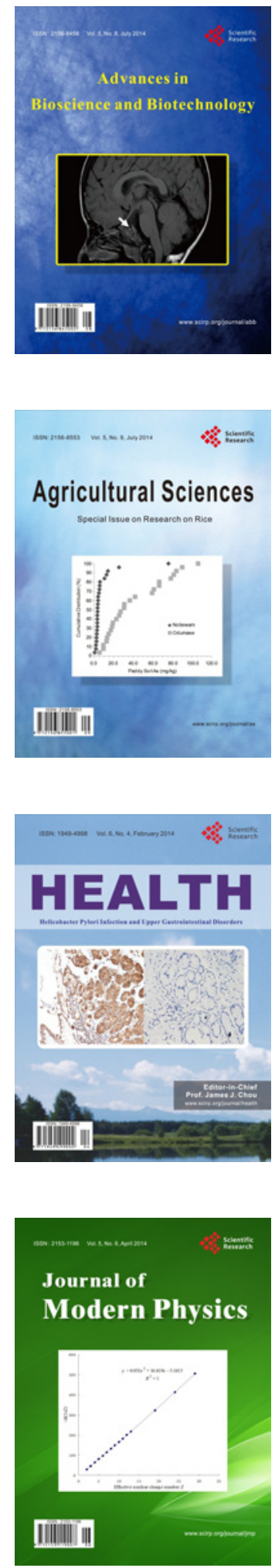
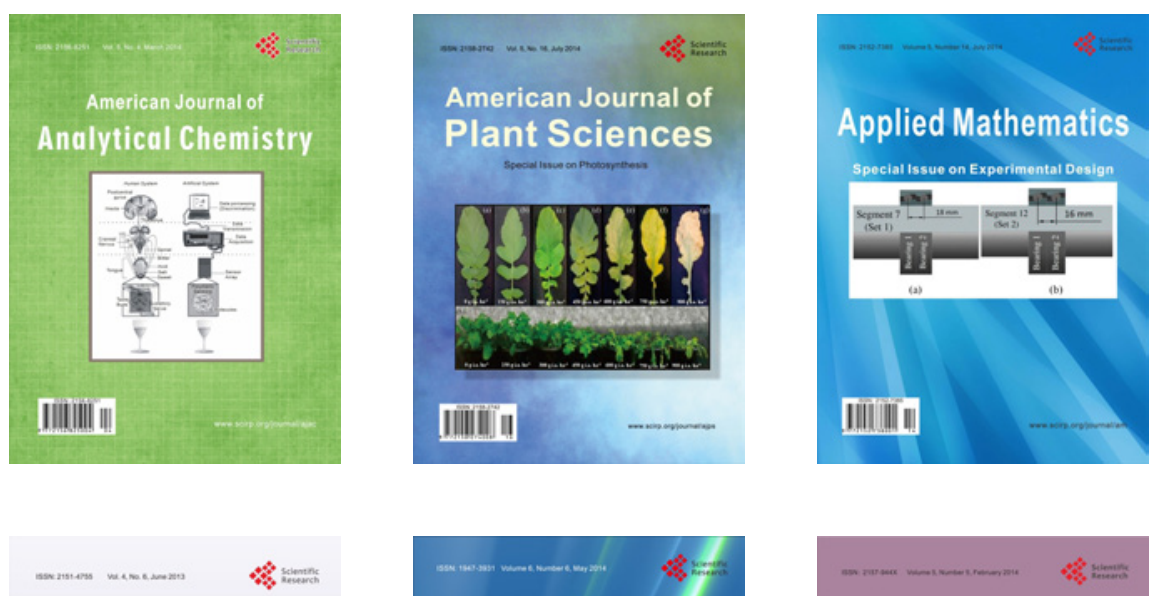

Creative Education
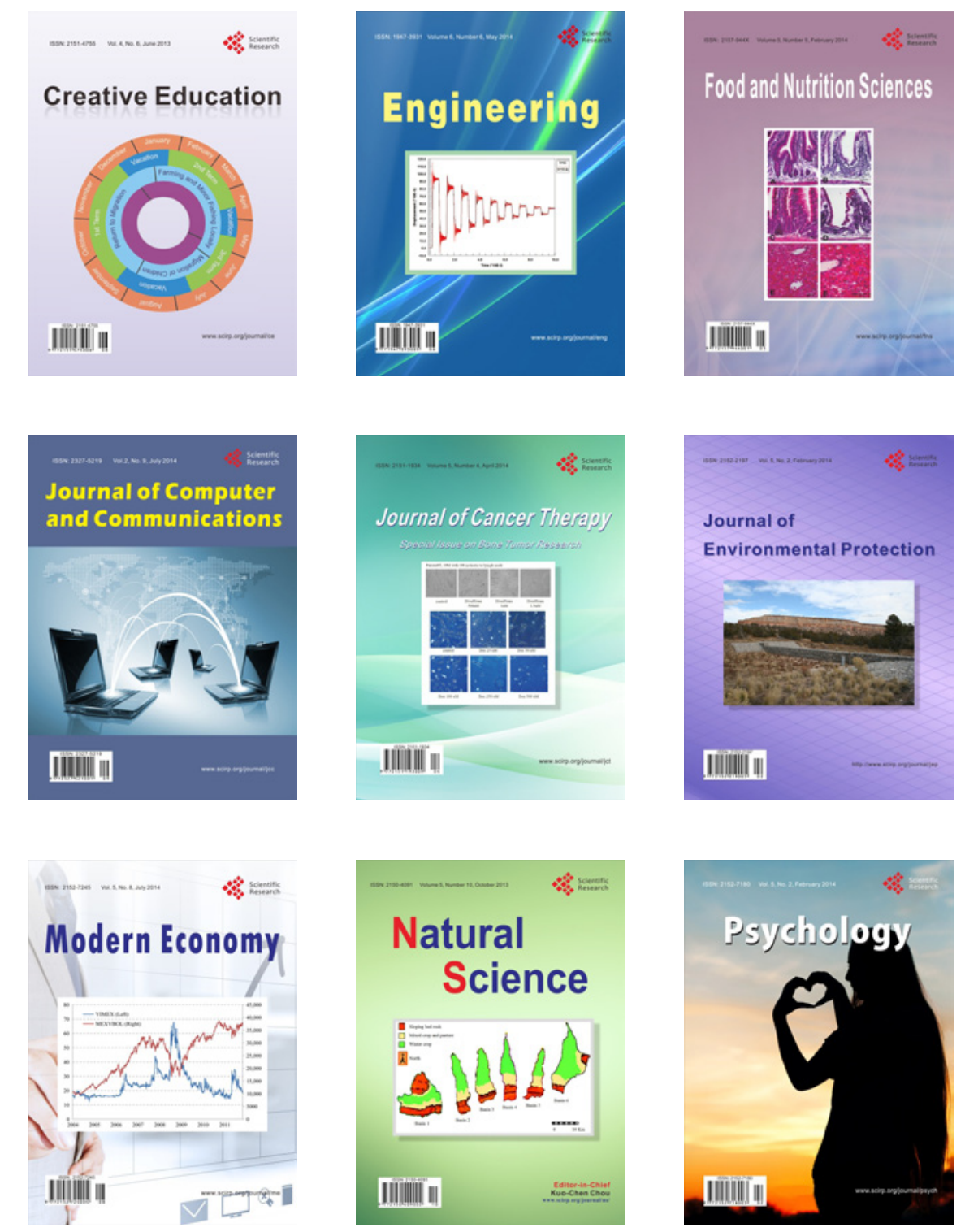